\title{
Os Fatores Determinantes do Pagamento de Dividendos: o Efeito do Obrigatório Mínimo Legal e Contratual nas Empresas Brasileiras
}

(The Determinants of Dividend Payment: the Effect of the Legal and Contractual Obligatory Minimum in Brazilian Companies)

\author{
Daniel Francisco Vancin* \\ Jairo Laser Procianoy**
}

\begin{abstract}
Resumo
Este estudo busca identificar os efeitos do dividendo obrigatório mínimo legal e contratual nos fatores determinantes das companhias listadas na BM\&FBovespa a pagar dividendos, demonstrando que a metodologia proposta representa um avanço na busca destes determinantes, espelhando a realidade do desejo efetivo de pagar. Para alcançar este objetivo foi construído um modelo tobit com variáveis instrumentais, segregando a amostra em três grupos: a Amostra Completa, grupo ACIMA e grupo MÍNIMO. No total, foram analisadas 1531 distribuições de dividendos no período de 2007 a 2013. Verificou-se a existência de fortes evidências empíricas que as empresas pagantes de dividendos acima do obrigatório legal e contratual apresentam fatores determinantes diferentes daquelas que pagam apenas este. Dessa forma, a existência de empresas na amostra que pagam apenas o dividendo obrigatório influencia nos coeficientes da regressão quando olhamos todos os grupos de forma conjunta, acarretando vieses importantes para a pesquisa de determinantes de dividendos no Brasil. Isto porque as empresas que pagam acima do obrigatório legal e contratual são as reais tomadoras da decisão de pagar dividendos, visto que empresas que pagam apenas o obrigatório simplesmente cumprem a legislação.
\end{abstract}

Palavras-chave: Dividendo, Lei, Brasil.

Códigos JEL: C26, G35, K10.

Submetido em 27 de julho de 2015. Reformulado em 24 de dezembro de 2015. Aceito em 16 de fevereiro de 2016. Publicado on-line em 21 de Abril de 2016. O artigo foi avaliado segundo o processo de duplo anonimato além de ser avaliado pelo editor. Editor responsável: Paulo Renato Soares Terra.

*Universidade Federal do Rio Grande do Sul. E-mail: daniel_vancin@hotmail. com

**Universidade Federal do Rio Grande do Sul e Universidade do Vale do Rio dos SinosE-mail: jairo.procianoy@ufrgs.br \footnotetext{
Rev. Bras. Finanças (Online), Rio de Janeiro, 14, No. 1, March 2016, pp. 89-123
ISSN 1679-0731, ISSN online 1984-5146

(C)2016 Sociedade Brasileira de Finanças, under a Creative Commons Attribution 3.0 license -

http://creativecommons.org/licenses/by/3.0
} 


\section{Abstract}

This study seeks to identify the effects of the mandatory dividend in determinants of companies listed on the BM\&FBovespa to pay dividends, demonstrating that the methodology proposed is a step forward in the pursuit of these determinants, mirroring the reality of actual willingness to pay. To accomplish this was used a tobit model with instrumental variables, separating the sample into three groups: the Complete Sample, ABOVE group and MINIMUM group. In total, were analyzed 1531 dividend distributions from 2007 to 2013. It was found that there is strong empirical evidence that companies paying dividends above the mandatory feature different determinants of those who only pay this. Thus, the existence of companies in the sample who pay only the mandatory dividend influence on the regression coefficients, resulting in significant biases for dividend determinants in Brazil. Because companies that pay above mandatory are the real makers of the decision to pay dividends, as companies only pay the mandatory simply comply with the legislation.

Keywords: Dividend, law, Brazil.

\section{Introdução}

O dividendo é uma parcela do lucro líquido das empresas que é distribuída aos investidores, como uma forma de remuneração do capital investido. O montante a ser pago e a forma de distribuição são decisões complexas que geraram inúmeras pesquisas a respeito. Divergências ocorrem desde os primeiros trabalhos sobre o assunto, como a proposta de relevância dos dividendos estudada por Lintner (1962) e Gordon (1963) em oposição a de irrelevância criada por Miller \& Modigliani (1961).

Os fatores que influenciam a distribuição de dividendos, tais como legislação e tributação, variam de país para país. Assim, devem ser consideradas as diferentes características de cada ambiente institucional ao executar um trabalho sobre o tema. No Brasil, a lei que normatiza o pagamento de dividendos é a lei 6.404/1976, nomeada Lei das Sociedades por Ações (LSA). Esta estabelece que acionistas têm direito de receber como dividendo obrigatório, em cada exercício, uma determinada parcela dos lucros da empresa.

A LSA estabelece em seu artigo 202 que acionistas têm direito de receber como dividendo obrigatório, em cada exercício, a parcela dos lucros estabelecida no estatuto, ou se este for omisso, a importância será a metade do lucro líquido contábil do exercício diminuído ou acrescido dos seguintes valores:

a) Quota destinada à constituição da reserva legal; 
b) Importância destinada à formação de reservas para contingências e reversão das mesmas reservas formadas em exercícios anteriores; e,

c) Lucros a realizar transferidos para a respectiva reserva e lucros anteriormente registrados nessa reserva, que tenham sido realizados no exercício.

No segundo inciso do mesmo artigo, é estabelecido que, em caso do estatuto não ser omisso em relação à sua distribuição, o dividendo obrigatório mínimo não poderá ser inferior a $25 \%$ do lucro líquido ajustado.

Conforme o artigo 193 da LSA, 5\% do lucro líquido do exercício serão aplicados, antes de qualquer outra destinação, na constituição da reserva legal, a qual não poderá exceder $20 \%$ do capital social, e tem por finalidade assegurar a integridade do capital social sendo utilizada exclusivamente para compensar prejuízos ou aumentar capital. Já o artigo 194 da mesma lei, determina que a assembleia geral poderá destinar parte do lucro líquido à formação de reservas para contingências, possuindo a finalidade de compensar, em exercício futuro, a diminuição do lucro decorrente de perda julgada provável. A reserva de lucros a realizar poderá ser constituída no exercício em que o montante do dividendo obrigatório ultrapassar a parcela realizada do lucro líquido do exercício.

O objetivo de estabelecer um dividendo obrigatório mínimo ${ }^{1}$ seria a proteção do acionista minoritário, ao impedir a possibilidade do controlador reter a totalidade dos lucros (La Porta et al. (2000), Coelho (2002)). Paralelamente, teria também a função de fortalecer o mercado de capitais ao garantir ao investidor uma remuneração mínima ao seu capital. Procianoy (2006) ressalta a importância desse mecanismo ao verificar que, no Brasil, há uma tendência das empresas em reter a maior parcela possível dos lucros, como forma de autofinanciamento em função da escassez de recursos para o financiamento de longo prazo das companhias naquele momento.

Uma preocupação do direito comercial é a proteção da minoria nas sociedades por ações. Por muitas vezes, os acionistas majoritários cortam a distribuição de dividendos com o objetivo de aumentar a parte retida a fim de manter o poder sobre uma maior quantidade de recursos já que estes ficam no caixa da empresa e os dividendos vão para o bolso dos acionistas. Contra essa prática, a lei em seu texto não oferece corretivo (Requião

\footnotetext{
${ }^{1}$ É bom atentar que o dividendo obrigatório mínimo objeto deste trabalho é a parte maior entre o que estabelece a lei e o que está no estatuto social das empresas examinadas. Não podemos confundir este com o conceito americano de dividendo mínimo, que é o montante fixo - em dinheiro ou percentual relativo ao valor nominal da ação - que é devido aos acionistas das companhias.
} 
(2011)). O autor relata ainda que a assembleia geral pode determinar o não pagamento dos lucros verificados no exercício, em função de motivos especiais, constituindo fundos de reserva com os mais diversos títulos criados.

Conforme o exposto, o dividendo obrigatório mínimo possui grande influência na política de dividendos no Brasil. As companhias de capital aberto possuem a obrigação de distribuir uma parcela pré-estabelecida de seus lucros. Apesar disto, a influência da existência de um dividendo mínimo não tinha sido considerada nos estudos anteriores sobre os determinantes do pagamento de dividendos, como $^{2}$ (Heineberg \& Procianoy (2003), da Silva (2004), Iquiapaza et al. (2005, 2006), Mota \& Eid Junior (2007), Ferreira Júnior et al. (2010), Forti et al. (2014)). Em comum, estas pesquisas utilizaram modelos de regressão para identificar fatores que tenham relevância e influência no processo decisório de pagamento de proventos, analisando uma gama diversificada de variáveis independentes. Porém, estas pesquisas não consideraram a questão legal e contratual do tema e as eventuais consequências no processo decisório do pagamento de dividendos, quando da existência de um dividendo obrigatório mínimo.

Segundo a tabela 1, os diversos artigos anteriores utilizaram em seus modelos de regressão como variável dependente o Payout de dividendos (da Silva (2004), Iquiapaza et al. (2006)), ou variações como o Dividend Yield Ferreira Júnior et al. (2010), o montante total (Heineberg \& Procianoy (2003), Iquiapaza et al. (2005)) ou a razão entre dividendos e patrimônio líquido Forti et al. (2014). Dessa forma, buscaram explicar os fatores que influenciam o pagamento de dividendos através do montante total pago aos acionistas, negligenciando o fato de que existe um dividendo obrigatório mínimo. A existência do dividendo mínimo legal e contratual acarreta no pagamento compulsório de uma parcela dos lucros das empresas. Essa parcela é obrigatória, não cabendo às empresas a opção de pagá-la ou não.

Ao compararmos todos os estudos que utilizam a metodologia tradicional para fatores determinantes de dividendos outros dados interessantes podem ser ressaltados. Percebe-se uma uniformidade com relação aos sinais dos coeficientes das variáveis dentre os estudos analisados, com exceção para as variáveis Market-to-book entre Ferreira Júnior et al. (2010) e Heineberg \& Procianoy (2003) e Forti et al. (2014) e Instabilidade de Receitas

\footnotetext{
${ }^{2}$ Pesquisas como Heineberg \& Procianoy (2003) foram realizadas em momento histórico anterior à profusão de fundos de private equity e de IPOs, como também do movimento de governança corporativa. Este fato pode influenciar nos resultados dessas pesquisas. Porém, para fins do presente trabalho, a legislação daquele momento e a atual são muito semelhantes, permitindo comparações.
} 
entre Mota \& Eid Junior (2007) e Ferreira Júnior et al. (2010), por exemplo. Nestes dois casos, este fato pode ser explicado, parcialmente, pelas diferenças entre proxies utilizadas para a definição das variáveis dependentes. Similarmente, duas variáveis mostraram sinais diferentes, apesar de possuírem a mesma variável dependente - Payout. Este fato ocorreu em Iquiapaza et al. (2006) e Mota \& Eid Junior (2007), nas variáveis Crescimento de Receita e Concentração Acionária. Este fato pode ser explicado, parcialmente, pelos diferentes anos amostrais e número de eventos da amostra em cada trabalho. Dessa forma, com base nos estudos analisados, existe uma tendência que as variáveis lucratividade, liquidez, tamanho, instabilidade das receitas, estabilidade dividendos, setor, crescimento da receita líquida, fluxo de caixa impactem positivamente na distribuição de dividendos das empresas brasileiras. Em oposição, as variáveis endividamento, inflação, q de Tobin e concentração acionária tendem a impactar negativamente nos dividendos. 


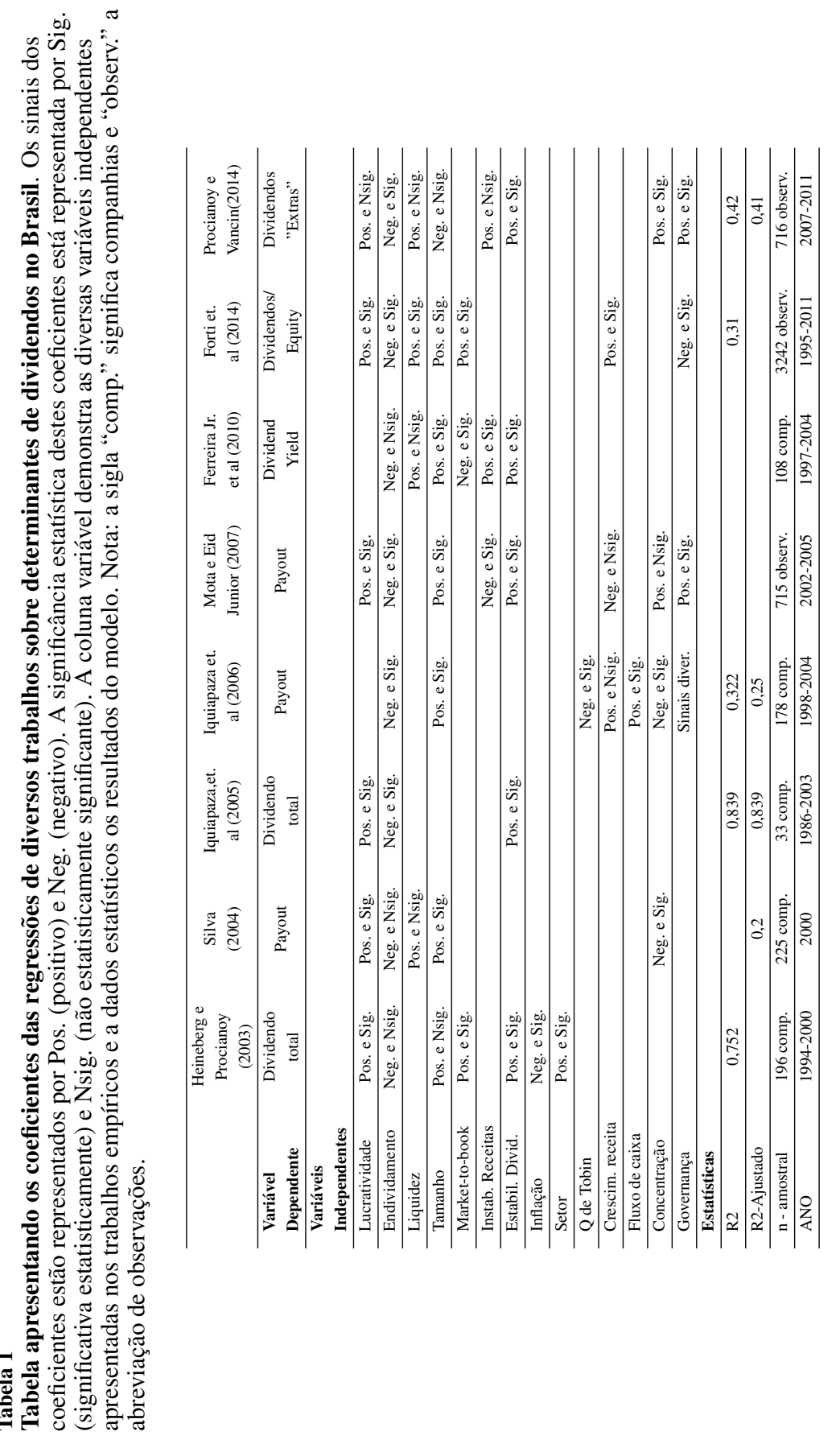


As companhias listadas na bolsa brasileira têm a obrigação, e não a opção, de distribuir uma parcela preestabelecida de seus lucros. Da mesma forma, algumas empresas, como consequência da vontade de seus acionistas, em algum momento ao longo do tempo, decidiram estabelecer um montante mínimo a ser pago como dividendos em seus estatutos sociais superior ao estabelecido pela lei. Com esta atitude temos o legal mínimo e o contratual mínimo. Ambos são uma obrigação e não uma opção no momento de decidir o montante a ser pago como dividendos. Observa-se no mercado de capitais nacional, entretanto, que algumas companhias - através da decisão de seus acionistas - optam por distribuir valores acima do valor legal e contratual mínimo, representando um diferencial importante.

Existe uma diferença básica entre as empresas que pagam o legal e o contratual mínimos e aquelas que pagam acima deste valor. Observa-se que as primeiras são compelidas por lei ou por seus estatutos sociais a fazerem algum pagamento de dividendos e que as segundas não o são. As primeiras, caso elas pudessem pagar menos que estes obrigatórios, muito provavelmente o fariam. A realidade brasileira no que tange a baixa disponibilidade de recursos de longo prazo para o financiamento das atividades de investimentos das empresas é um grande incentivador da alta retenção de caixa pelas empresas como forma de financiamento do crescimento. As empresas são contingenciadas no valor mínimo, mas não no valor máximo. O desejo de pagar só é encontrado naquelas que pagam acima destes mínimos.

Neste sentido, Procianoy \& Vancin (2014) abordaram os fatores que influenciam no pagamento de dividendos sob uma nova perspectiva, levando em consideração a questão legal e a contratual sobre o assunto. Companhias que distribuem apenas o dividendo obrigatório mínimo estão simplesmente cumprindo a legislação e os seus estatutos sociais. Entretanto, empresas que pagam acima deste montante sinalizam ao mercado que esta decisão foi tomada com base em critérios próprios, sem nenhuma obrigatoriedade. Para identificar os verdadeiros determinantes no pagamento de dividendos de empresas brasileiras, os autores criaram um modelo de regressão múltipla. Neste modelo a variável dependente foi calculada para representar a porção extra de dividendos, ou seja, a parcela superior ao mínimo de dividendos exigidos na lei e nos estatutos sociais. Foi verificado que o endividamento, investimento, concentração, governança corporativa e estabilidade da política de dividendos, influenciam as empresas listadas na bolsa de valores brasileira a pagar proventos acima do mínimo obrigatório, ou seja, apresentam as características determinantes daquelas empresas que 
resolveram pagar acima do mínimo legal e contratual. A amostra do estudo compreendeu 1118 eventos, atas de Assembleias Gerais Ordinárias (AGOs) entre os anos de 2007 e 2011.

A influência do dividendo obrigatório mínimo é importante para a compreensão do tema no Brasil, e sua não consideração pode induzir a fatores determinantes equivocados. O presente estudo tem como finalidade principal a identificação dos efeitos da consideração do dividendo obrigatório mínimo legal e contratual nos fatores que influenciam companhias listadas na BM\&FBovespa a pagar dividendos. Demonstra-se assim que a metodologia proposta representa um avanço na busca destes determinantes, espelhando a realidade do desejo efetivo de pagar acima de suas obrigatoriedades. Para tal, foi escolhida como variável dependente o Payout afim de possibilitar a comparação com as pesquisas anteriores. As empresas foram segregadas em três grupos, sendo um a amostra total, e dois grupos nos quais segmentou-se a amostra entre as empresas que pagam apenas o montante do dividendo obrigatório daquelas que distribuem valores superiores a este. O objetivo dessa segmentação é caracterizar as empresas constituintes de cada grupo e, principalmente, demonstrar o impacto da não consideração do dividendo obrigatório nos modelos estudados nesta pesquisa e nas anteriores sobre o tema.

Como em torno de $37 \%$ dos eventos do grupo total pagam o mínimo legal e contratual, ou menos que estes, e pela baixa variabilidade do índice Payout deste grupo, temos que este fato gera um forte impacto causando problemas no dimensionamento dos coeficientes explicativos das variáveis independentes, quando regredidos para a variável dependente Payout na amostra total.

Para a realização deste estudo foram estudados os estatutos sociais das companhias brasileiras de capital aberto com o intuito de determinar o pagamento mínimo obrigatório de dividendos de cada uma das empresas, legal e contratual. Após, as atas das assembleias gerais ordinárias destas empresas foram analisadas e se encontrou quais as que pagaram dividendos acima do valor mínimo obrigatório, e quais as que pagaram apenas este ou menos.

Os resultados obtidos indicam a existência de fortes evidências empíricas que as empresas que pagam dividendos acima do obrigatório legal e contratual são diferentes das empresas que pagam apenas este. Dessa forma, a existência de empresas na amostra que pagam apenas o dividendo obrigatório influencia nos coeficientes da regressão, acarretando vieses impor- 
tantes para a pesquisa de determinantes de dividendos no Brasil.

Esta pesquisa é relevante para o estudo de dividendos no Brasil, pois demonstra a importância e o impacto da não-consideração do dividendo obrigatório legal e contratual nos fatores determinantes do seu pagamento ou distribuição. A compreensão dos reais fatores determinantes de dividendos auxilia na compreensão do processo decisório das empresas e no real entendimento do fenômeno da política de dividendos no Brasil. Assim, é uma evolução comparada às outras pesquisas sobre o tema. Este avanço representa a abertura de novas fronteiras de pesquisa possibilitando a adequação dos modelos internacionais à realidade brasileira e a clareza necessária para o real entendimento do fenômeno.

A próxima seção apresenta metodologia proposta. A coleta de dados e a amostra são apresentadas na seção 3, os resultados da pesquisa na seção 4. A última parte sintetiza as conclusões do estudo.

\section{Metodologia}

Em 1961, Franco Modigliani e Merton Miller - também conhecidos por M\&M - publicaram um trabalho clássico onde argumentam, através de uma revisão teórica, que dividendos são irrelevantes em um mercado perfeito. Por perfeito entenda-se sem atritos: impostos, custos de negociação ou outras imperfeições de mercado.

Esta teoria defende a hipótese de que o pagamento de dividendos não altera o valor da firma nem a riqueza de seus acionistas. $\mathrm{O}$ valor da firma seria determinado pela sua política de investimentos e pelo retorno obtido por seus ativos. Assim, seus investidores seriam indiferentes quanto à origem do seu lucro: seja ele via dividendos, ou por ganhos de capital via valorizações de suas ações. Consequentemente, o que deveria importar aos investidores seria o aproveitamento dos projetos de valor presente líquido positivo segundo a política de investimentos das empresas. Sendo assim, não haveria diferença para os acionistas se a empresa financiasse o novo projeto de investimento cortando dividendos (financiamento interno) ou emitindo novas ações (financiamento externo).

O conceito-base que suporta a teoria de relevância de dividendos é atribuído a Gordon (1963) e Lintner (1962). Os autores sugerem a existência de uma relação direta entre a política de dividendos de uma empresa e seu valor de mercado. Suas ideias e argumentos ficaram conhecidos pela expressão "pássaro-na-mão", pois sugere que investidores são geralmente avessos ao risco. Assim, atrelam menos risco aos dividendos correntes do 
que a dividendos futuros ou títulos a pagar, ou seja, mais vale um pássaro na mão do que dois voando.

Outras importantes indagações sobre a função e as consequências da distribuição de dividendos começaram a ser feitas na pesquisa clássica de Black (1976), sobre o que o autor intitula "dividend puzzle". O autor questiona as razões pelas quais as empresas distribuem dividendos ao invés de aplicar este fluxo de caixa excedente em projetos economicamente vantajosos às companhias e aos acionistas. E é neste ponto que se inicia o dilema dos gestores: por um lado, as corporações pagam dividendos para premiar os acionistas pelo seu capital investido. Por outro lado, empresas que não distribuem demonstram confiança em suas oportunidades de investimento que poderiam ser perdidas caso fossem pagos dividendos.

A partir destas pesquisas clássicas muitas outras as seguiram no intuito de compreender a política de dividendos. Da mesma forma, esta pesquisa busca agregar conhecimento à um processo que ainda não foi totalmente compreendido pelo campo de pesquisa financeiro. Com este intuito, na presente seção serão abordados os aspectos metodológicos da pesquisa realizada, descrevendo brevemente as técnicas utilizadas para cumprir com os objetivos da pesquisa.

\subsection{Variável Dependente}

A variável dependente será o percentual de dividendos pagos sobre o lucro liquido ajustado das companhias (Payout). Esta variável dependente representa o montante pago aos seus acionistas e o diferencial retido pela companhia para financiamento de seu crescimento. Esta formulação da variável dependente foi muito utilizada em pesquisas passadas sobre o tema ${ }^{3}$. A variável dependente é calculada conforme equação 1 .

$$
\text { Payout }_{t}=\operatorname{div}_{t} / L L A_{t}
$$

Onde:

div = montante total do dividendo pago pela companhia referentes ao período $\mathrm{t}$; e,

LLA = lucro líquido ajustado da companhia no período t.

Sobre a variável dependente dos trabalhos citados anteriormente na tabela 1, algumas considerações devem ser feitas. As pesquisas de Heineberg

\footnotetext{
${ }^{3}$ Ver da Silva (2004), Iquiapaza et al. (2006), Mota \& Eid Junior (2007). 
\& Procianoy (2003) e Iquiapaza et al. (2005) utilizam o montante total de dividendos pagos. Esta metodologia traz um importante problema de mensuração, o da endogeneidade. A existência deste problema ocorre pelo fato de que a variável explicativa é determinada pela variável explicada do modelo. Empresas que pagam maiores dividendos (em termos de quantia monetária total), são geralmente as maiores empresas, ou seja, há endogeneidade entre a variável dependente e a variável tamanho, por exemplo. $\mathrm{O}$ problema poderia ser resolvido pelo uso de um índice na variável explicada, como o Payout, Dividend Yield, Dividendos sobre Patrimônio Líquido ou Dividendos sobre o Ativo Total. Dessa forma, durante a preparação dos dados da pesquisa, não é adequado o uso de variáveis que não estejam relativizadas ou normalizadas, dado o efeito tamanho que pode vir a prejudicar fortemente os resultados obtidos, causando conclusões equivocadas.

Procianoy \& Vancin (2014) estudaram a porção extra (quantidade distribuída acima do obrigatório) de dividendos nos fatores determinantes. Nosso estudo foca a diferenciação dos grupos, através de uma variável dependente utilizada na maioria dos trabalhos do tema.

\subsection{Variáveis Independentes}

As variáveis independentes selecionadas para o estudo foram as mesmas utilizadas em Procianoy \& Vancin (2014) e escolhidas com base nas evidências encontradas nos trabalhos de Lintner (1962), Alli et al. (1993), Fama \& French (2001), Heineberg \& Procianoy (2003), Denis \& Osobov (2008), Brown \& Sum (2010).

O cálculo das variáveis independentes deste trabalho foi influenciada diretamente pelo artigo 132 da LSA. Este determina que nos 4 (quatro) primeiros meses seguintes ao término do exercício social, deverá haver uma assembleia geral com a finalidade de, entre outros, deliberar sobre a destinação do lucro líquido do exercício e a distribuição de dividendos. Ou seja, a deliberação sobre a destinação do lucro obtido na data t será realizada em $t+1$. Exemplificando, a AGO de uma empresa realizada em 2011 será referente à distribuição de lucros de 2010. Dessa forma, os dados contábeis extraídos serão referentes a data t, ou seja, referentes ao exercício social que originou a distribuição de proventos e não os da data em que foram deliberados. A seguir são apresentadas as formas de cálculo das variáveis utilizadas no estudo.

- ROE:

Variável que indica a lucratividade das companhias. O índice utili- 
zado será o de retorno sobre o patrimônio líquido, dado pela equação 2. Esse indicador financeiro, denominado ROE (Return on Equity), representa quanto uma empresa consegue gerar de lucro em relação ao capital investido.

$$
R O E_{t}=L L_{t} / P L_{t}
$$

Onde:

$L L_{t}=$ lucro líquido no período $\mathrm{t} ; \mathrm{e}$,

$P L_{t}=$ patrimônio líquido no período $\mathrm{t}$.

É esperada uma relação positiva entre lucratividade e a quantidade de dividendos distribuídos. Inclusive Heineberg \& Procianoy (2003) e Futema et al. (2009) a consideram como uma das variáveis com maior poder explicativo para o estudo dos determinantes de dividendos no Brasil. Estes autores encontraram fortes evidências empíricas que empresas com maior lucratividade tendem a pagar maiores proventos a seus acionistas.

- Endividamento (E):

Empresas com uma estrutura de capital composta por maior nível de alavancagem têm a obrigação de realizar pagamentos sobre as dívidas, reduzindo os recursos para distribuição de proventos. Assim, é esperada uma relação negativa entre essa variável independente com o pagamento de dividendos. O índice utilizado foi o endividamento total, dado pela equação 3 .

$$
E_{t}=\left(P C_{t}+E L P_{t}\right) / A T_{t}
$$

Onde:

$P C_{t}=$ passivo circulante do período t;

$E L P_{t}=$ exigível à longo prazo do período $\mathrm{t} ; \mathrm{e}$

$A T_{t}=$ ativo total do período $\mathrm{t}$.

Empiricamente, a pesquisa de Silva \& Brito (2005) demonstra a relação negativa entre dividendos e alavancagem, confirmando que estes são substitutos na alocação dos recursos internos da firma.

- Investimento (I):

Denis \& Osobov (2008) mensuram as oportunidades de investimento 
pela razão entre a variação do ativo total (entre t e t-1) e o próprio ativo total no ano anterior $\left(A T_{t-1}\right)$, como demonstra a equação 4 .

$$
I_{t}=\Delta A T_{t} / A T_{t-1}=\left(A T_{t}-A T_{t-1}\right) / A T_{t-1}
$$

Para a realização de novos investimentos, empresas necessitam de recursos. Dessa forma, opções de investimento e pagamento de dividendos aos acionistas estariam concorrendo pelos mesmos recursos. Assim, é esperada uma relação negativa entre ambos.

Esta visão contraria Fama (1974), o qual confirma a previsão de Miller e Modigliani que, num mercado de capitais perfeito, decisões de investimento de uma companhia não dependem das suas decisões de dividendos. Porém, há evidências na literatura sobre a imperfeição dos mercados, especialmente aqueles em desenvolvimento, como o Brasil. Dessa forma, pode-se esperar que as imperfeições do mercado brasileiro influenciem na existência de uma relação significativa entre investimento e dividendos.

- Tamanho da empresa $(\mathrm{T})$

Dado pelo logaritmo neperiano (ln) do ativo total, conforme equação 5. A transformação logarítmica da variável é utilizada para corrigir os efeitos de escala, tornando a variável homogênea.

$$
T_{t}=\ln \left(A T_{t}\right)
$$

É esperado uma relação positiva entre o tamanho da empresa e o montante distribuído em dividendos. Fama \& French (2001) reportam que empresas pagadoras de dividendos têm a tendência de serem maiores do que as empresas não pagadoras. Grandes empresas possuem maior facilidade para obtenção de crédito, o que asseguraria o financiamento para suas atividades, facilitando a distribuição de dividendos. De acordo com Redding (1997), a política de dividendos de uma companhia é determinada pelas preferências dos seus acionistas. Grandes investidores optariam por investir em grandes corporações, pois reduz os seus custos de transação. Uma vez que estas instituições preferem dividendos, as grandes corporações optar por pagar dividendos, enquanto as pequenas empresas, de propriedade de investidores individuais, não.

- Instabilidade das Receitas (INST REC)

Empresas com alta irregularidade nos ganhos (maior risco) provavel- 
mente terão menos comprometimento com o pagamento de dividendos devido o risco maior das receitas esperadas não venham a ocorrer (Aivazian et al. (2003)). O índice é calculado pelo desvio-padrão dos logaritmos naturais dos últimos 4 (quatro) anos de receitas operacionais das empresas da amostra. Uma relação negativa é esperada.

$$
I N S T_{-} R E C_{t}=\sigma[\ln (\overline{R E C})]
$$

Onde:

$R E C_{t}=$ receita operacional no período $\mathrm{t}$.

- Concentração (CONC)

A variável CONC foi criada com base no trabalho de Alli et al. (1993), e seu cálculo está relatado na equação 7.

$$
C O N C_{t}=\% \text { \%_ã̃es_ordinãrias_do_acionista_majoritãrio }
$$

Conforme Correia da Silva et al. (2004), existem pelo menos três razões pelas quais os padrões de controle acionário tem um substancial impacto na política de dividendos. Em primeiro lugar, acionistas controladores podem impor seu índice de payout preferido para todos os acionistas. A preferência por uma taxa específica pode ser influenciada pela tributação do acionista controlador. Em segundo, o principal controlador pode reduzir os dividendos em nome de outras formas de obter fluxos de caixa (benefícios privados). Por fim, o acionista controlador pode não ter que depender no efeito disciplinador de um alto payout como instrumento de governança ao passo que pode ser mais eficiente e menos custoso em monitorar a administração diretamente.

Neste contexto, empresas pulverizadas podem ter custos de agência severos, pois a existência de um grande acionista pode alinhar os interesses dos acionistas com a administração, reduzindo os custos de agência. Por outro lado, um alto payout de dividendos também pode diminuir estes custos, ao aumentar a possibilidade de financiamento externo, estando este provavelmente sujeito a monitoramento. Dessa forma, empresas concentradas podem diminuir a necessidade por dividendos para reduzir custos de agência, visto que os grandes acionistas monitoram a administração. Entretanto Morck et al. (1988) através de um estudo relacionando a propriedade (management ownership) e valor de mercado da empresa (Q de Tobin) sugerem que 
depois de certo ponto ("the point of entrenchment") o acionista controlador tende a buscar benefícios próprios às custas dos acionistas minoritários.

Empiricamente, Hahn et al. (2010) demonstraram que em empresas brasileiras que pagaram dividendos acima de $25 \%$, existe relação entre a concentração acionária e o Payout, e essa relação é positiva, ou seja, quanto maior a concentração acionária maior o nível do Payout. Resultados similares foram obtidos por Dalmácio \& Corrar (2007).

- Dividendo do Exercício Anterior (Div $\left.v_{t-1}\right)$

O trabalho pioneiro de Lintner (1956) demonstra em seu modelo que os dividendos presentes são determinados pelo dividendo passado e pelos lucros atuais. Desde este estudo, muitos estudos demonstraram a tendência, principalmente em mercados desenvolvidos, da estabilidade na política de dividendos. Gestores tendem a manter constantes as taxas de remuneração dos acionistas. A hipótese do "conteúdo informativo" de dividendos afirma que os administradores usam os anúncios de dividendos para sinalizar suas crenças sobre as perspectivas futuras da empresa (Bhattacharya et al. (1979)). Assim, um anúncio de um aumento na taxa de dividendos reflete a crença de uma melhora nos resultados da empresa. Da mesma forma, um anúncio de uma redução de dividendos ocorre apenas quando a administração é extremamente pessimista sobre os resultados futuros.

A implicação teórica da hipótese de "conteúdo informativo" no anúncio de um dividendo (ou mudança de dividendos), é a de que esta infor- mação pode causar uma reação imediata dos investidores, incluindo, mas não se limitando a, alterações de preços. Dessa forma, gestores teriam incentivos a manter constantes os pagamentos de dividendos.

Como proxy indicativa desta variável, será utilizado o Payout de dividendos do ano anterior como valor de referência no pagamento de proventos para o ano corrente. Dessa forma, é esperada uma relação positiva entre esta variável e a variável dependente.

$$
\operatorname{Div}_{t-1}=\$ d i v_{t-1} / L L A_{t-1}
$$

Onde:

$\$ d i v_{t-1}=$ montante do dividendo efetivamente distribuído pelas companhias no exercício anterior; e,

$L L A_{t-1}=$ lucro líquido ajustado do exercício anterior. 


\subsection{Regressão Múltipla}

Para verificar quais fatores (características das empresas) influenciam na opção das companhias brasileiras de capital aberto por pagar dividendos, foi construído um modelo tobit com variáveis instrumentais. O propósito fundamental de um modelo tobit é prever a variável dependente através de um conjunto de variáveis independentes (Hair et al. (2009)), especificamente quando a variável dependente é censurada, ou seja, não é livremente distribuída entre $-\infty$ e $+\infty$. Concomitantemente, o modelo também contém uma variável defasada e este fato pode acarretar problemas econométricos. Em um modelo econométrico, devido à provável correlação positiva entre a variável dependente defasada e o termo erro, a aplicação direta dos mínimos quadrados ordinários (MQO) produz estimativas dos coeficientes viesadas (Bond (2002)), fato corroborado nesta pesquisa pelo teste de Haussman. Para resolver este problema, também em uma pesquisa sobre fatores determinantes de dividendos, Frankfurter et al. (2003) sugerem o uso de variáveis instrumentais.

Após definida a variável dependente da regressão, é necessário apresentar a função matemática da regressão múltipla que buscará descrever o comportamento dessa variável. Cabe ressaltar que as variáveis independentes são as mesmas citadas na seção anterior, conforme demonstra a equação 9.

$$
\begin{array}{r}
\operatorname{Payout}_{(i, t)}=\beta_{0}+\beta_{1} R O E_{(i, t)}+\beta_{2} E_{(i, t)}+\beta_{3} T_{(i, t)}+\beta_{4} I_{(i, t)} \\
+\beta_{5} \operatorname{CONC}_{(i, t)}+\beta_{6} I N S T_{-} R E C_{(i, t)}+\beta_{7} \operatorname{Div}_{(i, t-1)}+\varepsilon
\end{array}
$$

Onde:

$\beta_{0}=$ intercepto do modelo;

$\beta_{1-7}=$ coeficientes das variáveis independentes;

$\mathrm{ROE}=$ retorno sobre o patrimônio liquido;

$\mathrm{E}=$ endividamento;

$\mathrm{T}=$ tamanho;

$\mathrm{I}=$ investimento;

CONC = concentração;

Inst_Rec = instabilidade das receitas;

Div $v_{t-1}=$ dividendo do exercício anterior;

$\varepsilon=$ termo erro.

Através deste modelo, procura-se identificar quais características e fato- 
res das empresas brasileiras "i" que influenciam na escolha pelo Payout de seus dividendos na data " $\mathrm{t}$ ".

Então a amostra é seccionada em três diferentes grupos e, dessa forma, gera três regressões distintas: uma regressão com a Amostra Completa, uma com empresas que pagaram apenas o obrigatório - grupo MÍNIMO, e outra pelas companhias que pagaram dividendos acima do obrigatório grupo ACIMA. O objetivo dessa segmentação é caracterizar as empresas constituintes de cada grupo e, principalmente, demonstrar a diferenciação dos resultados entre grupos. Para, com base nestes resultados, verificar o impacto do critério legal e contratual de dividendos sobre os seus fatores determinantes.

As observações atípicas (outliers) também devem receber atenção ao realizar uma regressão múltipla. São dados amostrais com valores extremos, tanto pequenos quanto grandes, que são bem diferentes do restante das observações (Downing et al. (1999), Good \& Hardin (2012)). Estes dados extremos podem influenciar significativamente na estimação dos parâmetros das variáveis. Para que não houvesse esta influência, foi realizada a winsorização das variáveis. Este método de tratamento de outliers consiste em aparar os valores extremos (acima ou abaixo dos percentis mínimos e máximos definidos), substituindo-os pelos valores menores e maiores remanescentes na distribuição Lusk et al. (2011). Neste estudo foi fixado como limite superior e inferior, $97,5 \%$ e 2,5\% respectivamente.

Adicionalmente, fazemos a comparação entre dois anos da nossa amostra com percentuais extremados para os grupos MÍNIMO e ACIMA, através de uma regressão tobit com variáveis instrumentais. Os eventuais resultados, se forem semelhantes, indicariam que o peso relativo do Grupo MÍNIMO sobre o ACIMA não são relevantes. Mas, caso sejam distintos, poderemos inferir a importância que os pesos relativos possam vir a ter nos resultados encontrados quando examinamos a amostra completa. Isto colocaria mais um elemento importante quando estudamos os fatores determinantes de dividendos e a necessidade da consideração do obrigatório mínimo legal e contratual das empresas brasileiras negociadas na BM\&FBovespa.

\section{Coleta de Dados e Amostra}

A amostra é composta por empresas brasileiras listadas na BM\&FBovespa que pagaram dividendos no período de 2007 a 2013. Os dados referentes às demonstrações contábeis dessas companhias foram extraídos do banco de dados da Economática $囚$. 
Uma vez definidas as empresas constituintes da amostra, seguiu-se para a classificação destas entre: empresas que pagam dividendos acima do obrigatório mínimo ou empresas que pagam apenas este. A legislação determina que o estatuto social das companhias possa determinar a parcela mínima do lucro distribuído via dividendos. Visto essa disposição legal, foi necessário para o cumprimento dos objetivos deste trabalho, a análise dos estatutos sociais das companhias listadas na BM\&FBovespa. No dia 31 de dezembro de 2014, existiam 496 companhias listadas na BM\&FBovespa. Os estatutos sociais analisados estão disponíveis no site da bolsa de valores, ou no próprio site oficial das companhias.

Ao analisar-se os estatutos sociais das 496 companhias, pôde-se verificar qual a parcela do lucro que deve ser destinado ao pagamento obrigatório de dividendos de cada uma delas. Com o intuito de verificar se este estava sendo pago ou não, utilizou-se do artigo 192 da LSA, o qual determina que a AGO deve aprovar a proposta de destinação do lucro líquido do exercício. Sendo assim, tornou-se necessária a leitura das atas das AGOs que aprovam a destinação dos dividendos, para relacionar os dividendos pagos ao exercício social que deu origem aos mesmos.

Dessa forma, ao analisar 496 companhias e seus estatutos sociais, foi verificado um universo de 3472 atas de AGOs ao longo dos sete anos amostrais. Somente foram incluídas neste estudo atas de empresas que pagaram dividendos, segundo o banco de dados da Economática $($. Das atas de empresas pagadoras de dividendos foram incluídas no presente estudo apenas aquelas que cumpriram os seguintes critérios: estar disponível pela BM\&FBovespa e ser de empresa listada em bolsa de valores. Ao todo, foram selecionadas e analisadas 1531 atas de AGOs no período estudado.

Após a leitura das atas, foi feita a comparação entre quanto foi aprovado pela AGO e quanto deveria, segundo a legislação e ao estatuto social de cada empresa, ser destinado aos acionistas como dividendo obrigatório. Ao realizar tal comparação, pôde-se determinar quais empresas estão pagando igual ou abaixo do obrigatório.

Ao analisar as atas das AGOs da amostra, percebeu-se que muitas empresas optaram por remunerar seus acionistas via juros sobre capital próprio (JSCP). Sobre esse assunto, Iudícibus et al. (2010) apontam duas questões relevantes: os JSCP podem ser imputados ao dividendo que trata o artigo 202 da LSA (ou seja, ao dividendo mínimo obrigatório), e só podem ser imputados líquidos de Imposto de Renda Retido na Fonte (IRRF). As afirmações feitas por esses autores são corroboradas pela lei 9.249/95 e pela 
deliberação 683 da Comissão de Valores Mobiliários (CVM).

A lei 9.249, principalmente em seu nono artigo, fixa os principais critérios legais para a utilização dos JSCP no Brasil:

- permitiu às empresas imputar os juros pagos a título de remuneração do capital próprio ao valor dos dividendos mínimos obrigatórios de que trata o artigo 202 da LSA;

- o pagamento de JSCP está condicionado à existência de lucros, computados antes da dedução dos juros, ou de lucros acumulados e reservas de lucros;

- são calculados com base no saldo das contas do patrimônio líquido e limitados à variação, pro rata dia, da Taxa de Juros de Longo Prazo (TJLP);

- concede vantagens fiscais à empresa ao remunerar seu acionista com JSCP, visto que estes são contabilizados como despesa financeira no resultado do exercício e passam a compor o lucro real.

A inserção dos JSCP nas demonstrações contábeis tornaria o lucro contábil mais próximo da visão econômica do resultado (Santos \& Salotti (2009)). Pois dessa forma, os demonstrativos contábeis contemplariam também a remuneração do capital próprio na apuração do lucro.

Foi necessário distinguir então, se o montante pago aos acionistas foi feito em forma de dividendos ou JSCP. Se pago via JSCP, se fez necessário o cálculo de seu valor líquido, já deduzidos os impostos. Muitas empresas já disponibilizam o valor líquido em suas atas, mas não a totalidade. No caso de não disponibilização, foi então convencionado a alíquota de $15 \%$ - igual a alíquota pessoa física - de Imposto de Renda Retido na Fonte (IRRF) sobre o JSCP. Este cálculo é desnecessário quando o pagamento for realizado via dividendos, visto que seu valor já é livre de impostos.

Percebe-se através dos dados da tabela 2 que, ao longo dos anos selecionados para o estudo, em 2008 houve o menor número de distribuições de dividendos (191) por parte das companhias brasileiras. Em contrapartida, 2010 possui o maior número de eventos, com 251 distribuições.

Pelo Payout médio do total de atas analisadas, pode-se inferir que, na média, as empresas brasileiras distribuem $48,6 \%$ do seu lucro líquido ajustado na forma de dividendos ou juros sobre capital próprio ao seus acionistas. Esta quantidade mantém-se constante ao longo dos anos estudados 
(de 44,3\% em 2012 à 51,1\% em 2008). E, através da análise do desviopadrão da amostra, pode-se inferir a existência de uma alta variabilidade $(0,27)$ na distribuição de proventos entre as empresas brasileiras, variando de 0,25 em 2012 a 0,28 em 2007, 2008, 2009 e 2011. Por isso concluímos que, no período estudado, as empresas pagam mais que os $25 \%$ do LLA contrariando a colocação de Procianoy (2006).

Outra questão importante extraída da análise da tabela 2 é a tendência das empresas brasileiras em pagar dividendos acima do obrigatório legal e contratual (63,3\% dos eventos). Essa proporção mantém constância ao longo dos anos selecionados para o estudo, tendo como mínimo o ano de 2012 (55,7\%) e o máximo o ano de 2009 (67,9\%). As companhias que pagaram dividendos acima do obrigatório tiveram um Payout médio ao longo do tempo dentro do intervalo de 59,1\% (2012) à 64,3\% (2008). Neste grupo de empresas, o desvio-padrão é bem mais alto $(0,27)$ que no grupo que paga apenas o dividendo obrigatório $(0,046)$. Assim, pode-se inferir que não há uma uniformidade na quantia destinada ao pagamento de proventos no grupo de empresas que pagam dividendos acima do obrigatório. 


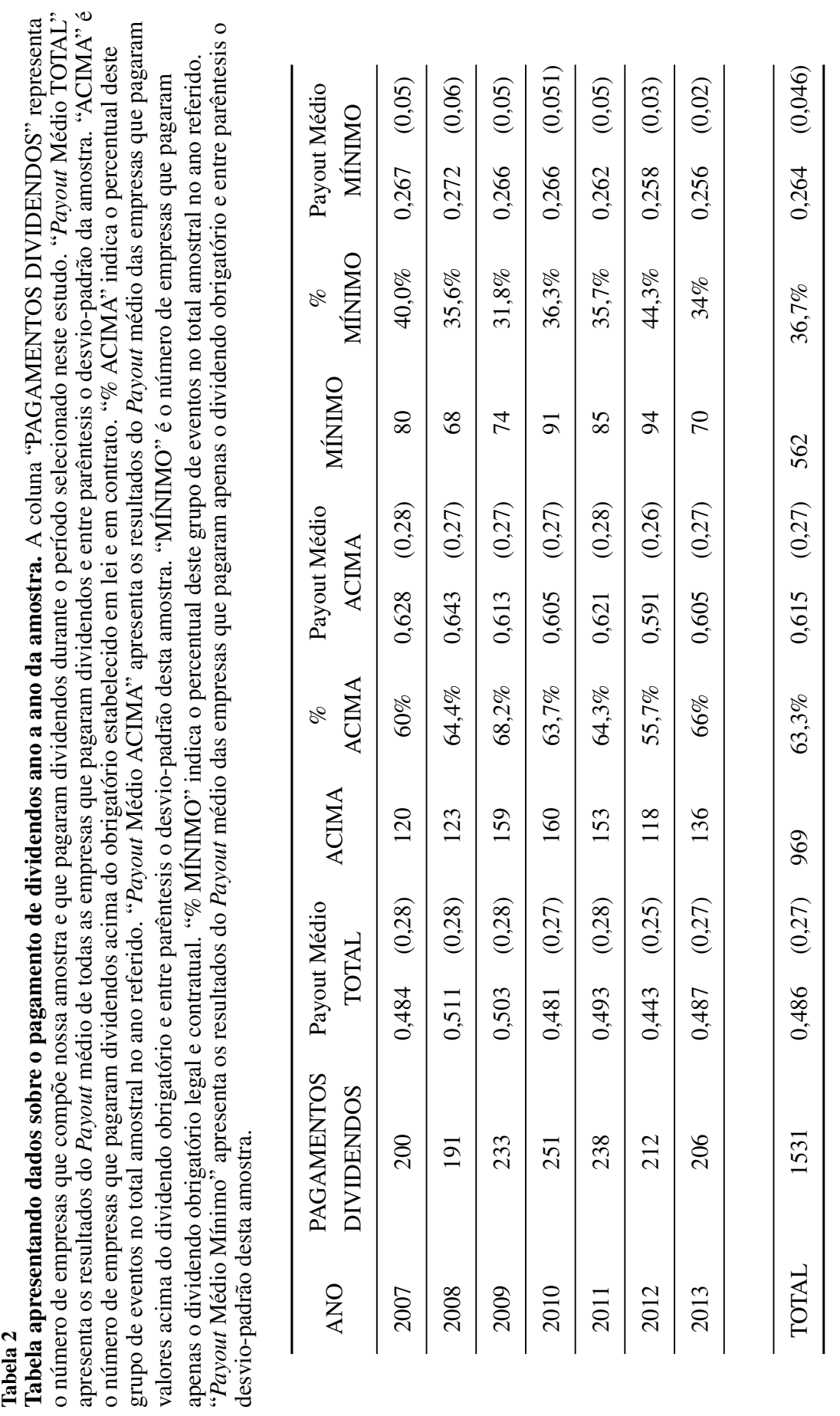

Rev. Bras. Finanças (Online), Rio de Janeiro, V14, No. 1, March 2016 
Uma proporção menor de empresas pagaram apenas o dividendo obrigatório legal e contratual (média de $36,7 \%$ durante o período de estudo), variando de 31,8\% em 2009 até 44,3\% em 2012. O Payout médio deste grupo foi de $26,4 \%$ e se manteve constante ao longo dos anos, com uma variabilidade de 0,046. Este fato é reflexo, provavelmente, do falso entendimento de integrantes do mercado de capitais que acreditam que $25 \%$ seja o patamar mínimo de dividendos segundo a legislação. Uma explicação para a existência desta crença está na própria legislação. O segundo inciso do artigo 202 da LSA estabelece que quando o estatuto for omisso e a assembleia-geral deliberar alterá-lo para introduzir norma sobre a matéria, o dividendo obrigatório não poderá ser inferior a $25 \%$ do lucro líquido ajustado. Sobre este dispositivo legal, Iudícibus et al. (2010) afirmam haver nuances na sua interpretação. Uma parcela da doutrina jurídico-societária compreende que, relativo às companhias constituídas após o dispositivo citado, não há obrigatoriedade de seus estatutos sociais conferirem a título de dividendo obrigatório $25 \%$ do lucro líquido ajustado, sendo livre sua fixação por parte das companhias e de seus acionistas.

É importante notar que a variabilidade do Payout médio do grupo MÍNI$\operatorname{MO}(0,046)$ é muito menor que a do grupo $\operatorname{ACIMA}(0,27)$. Disto depreendese que o comportamento do grupo MÍNIMO pode influenciar de forma diversa da Amostra Completa, quando examinamos os fatores determinantes da distribuição de dividendos das empresas brasileiras negociadas na BM\&FBovespa para uma amostra que considera a totalidade de empresas sem levar em conta a característica de mínimo obrigatório legal e contratual existente no mercado brasileiro. Com isto fica evidenciada a importância da consideração do obrigatório mínimo legal e contratual para o exame dos fatores determinantes no pagamento de dividendos no Brasil.

Em uma análise preliminar, para diferenciação dos grupos, a tabela 3 apresenta os dados das estatísticas descritivas das variáveis independentes ${ }^{4}$. Foram verificadas diferenças estatisticamente significativas (através do teste $t$ de diferença de médias) entre as médias de variáveis entre os grupos MÍNIMO e ACIMA. Empresas que pagam dividendos acima do obrigatório mínimo são caracterizadas por apresentarem maiores valores nas variáveis $R O E$, tamanho, concentração e dividendo do exercício anterior. Curiosamente, nestas mesmas variáveis, o grupo ACIMA também apresenta maiores desvios padrões para estas mesmas variáveis. Dessa forma, o

\footnotetext{
${ }^{4}$ Foi realizado a análise de correlação entre as variáveis, e não existe correlação alta entre nenhuma das variáveis.
} 
grupo ACIMA pode ser caracterizado por maiores valores nestas variáveis, mas também com maior volatilidade nas mesmas. 


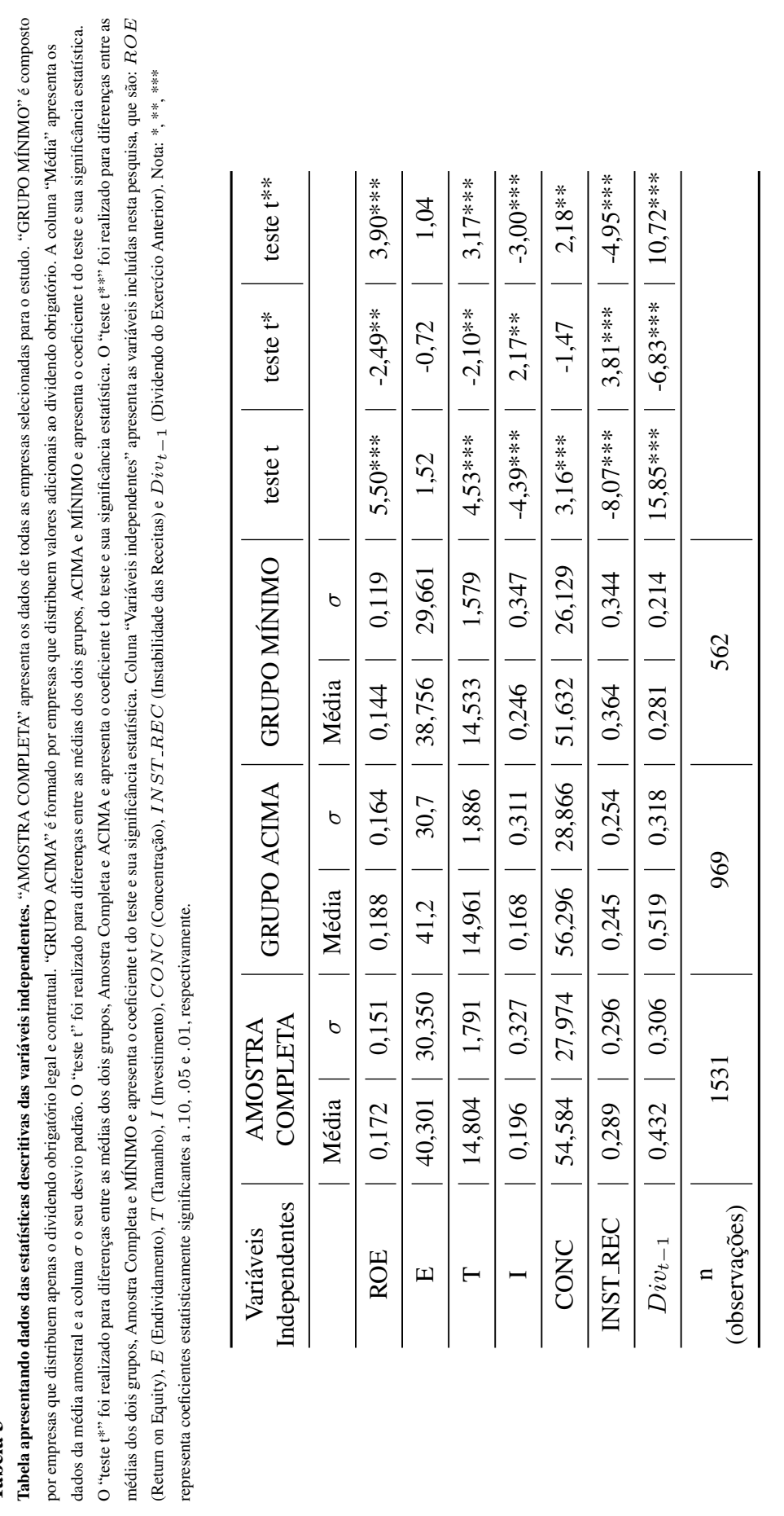


Do mesmo modo, o grupo de empresas que pagam apenas o obrigatório legal e contratual apresentam maiores valores, com diferença estatisticamente significante nas variáveis investimento e instabilidade de receitas. E, da mesma forma, o grupo MÍNIMO também apresenta menores desviospadrões para estas mesmas variáveis. Assim, o grupo ACIMA pode ser caracterizado por menores valores nestas variáveis, mas também com menor volatilidade nas mesmas. O grupo MÍNIMO é coerente com os achados em outros estudos, pois com maior investimento estas empresas retem o máximo possível do lucro para financiar seus investimentos futuros na medida em que as fontes de recursos de longo prazo são mais escassas. Ao mesmo tempo vemos que a noção de risco do negócio está presente na variável instabilidade das receitas agindo como um desincentivo para o pagamento maior de dividendos.

A exceção é a variável Endividamento (E) por ser estatisticamente igual, de acordo com teste $t$ de médias, entre os três grupos do estudo. Dessa forma, não pode-se inferir que haja distinções para caracterização da amostra nesta variável entre as empresas que pagam apenas o mínimo legal e contratual daquelas que pagam acima deste.

Através de uma inspeção visual da tabela 3 , pode-se perceber que a média das diversas variáveis independentes da Amostra Completa assemelhase muito mais às estatísticas do grupo de empresas que pagam acima do dividendo mínimo obrigatório legal e contratual (ACIMA). Este fato pode ser explicado pelo representação maior que este grupo tem na amostra total.

Estes resultados da análise descritiva dos dados demonstram preliminarmente que existem diferenças significativas entre empresas que pagam apenas o dividendo mínimo daquelas que pagam acima, e que a realização de um estudo tomando-se a Amostra Completa pode apresentar alguma distorção em função de uma maior ou menor participação do grupo MíNIMO.

\section{Resultados}

É escopo desta pesquisa avaliar o impacto do dividendo obrigatório mínimo nos fatores determinantes do pagamento de dividendos das empresas brasileiras. Para tal, tomamos o Payout como variável dependente para que fosse possível comparar com a literatura existente e, ao segmentarmos a amostra, identificarmos a influência do grupo que paga o mínimo legal e contratual ou menos que este.

Para expandir a compreensão do tema, a equação 9 descreve o modelo 
Tabela 4

Tabela apresenta os resultados de uma regressão múltipla onde a variável dependente são os Payouts das empresas selecionadas na amostra. Coluna "Variáveis independentes" apresenta as variáveis incluídas neste modelo de regressão múltipla, que são: $R O E$ (Return on Equity), $E$ (Endividamento), $T$ (Tamanho), I (Investimento), $C O N C$ (Concentração), INST_REC (Instabilidade das Receitas) e Div $v_{t-1}$ (Dividendo do Exercício Anterior). A coluna "Amostra Completa" apresenta os coeficientes das variáveis independentes de todas as empresas da amostra. A coluna "Grupo MíNIMO" representa os coeficientes do sub-grupo de empresas que pagaram apenas o dividendo obrigatório legal e contratual. A coluna "Grupo ACIMA" apresenta os coeficientes do sub-grupo de companhias que pagaram dividendos acima do obrigatório. Dados faltantes foram omitidos automaticamente pelo modelo por questões de multicolinearidade. Nota: $*, * *, * * *$ representa coeficientes estatisticamente significantes a $.10, .05$ e 0.1 , respectivamente.

\begin{tabular}{cccc}
\hline $\begin{array}{c}\text { Variáveis } \\
\text { Independentes }\end{array}$ & Am. Completa & Gr. ACIMA & Gr. MÍNIMO \\
\hline constante & $(0,094)$ & $0,278^{* * *}$ & $(0,186)$ \\
\hline ROE & 0,024 & 0,02 & 0,038 \\
\hline $\mathrm{E}$ & 0,0005 & $(0,0003)$ & $0,001^{*}$ \\
\hline $\mathrm{T}$ & 0,007 & $(0,005)$ & 0,007 \\
\hline $\mathrm{I}$ & $(0,068)^{* *}$ & $(0,031)$ & $(0,017)$ \\
\hline CONC & 0,0003 & 0,0005 & $(0,001)^{*}$ \\
\hline INST_REC & $(0,106)^{* * *}$ & $(0,006)$ & $(0,083)$ \\
\hline Div ${ }_{t-1}$ & $0,94 * * *$ & $0,737 * * *$ & $0,419 * *$ \\
\hline Estatísticas Descritivas & & & \\
\hline n (observações) & 1531 & 969 & 562 \\
\hline Log Verossimilhança & $(70,72)$ & 200,85 & 82,42 \\
\hline Média Var. Dependente & 0,4858 & 0,6147 & 0,2636 \\
\hline
\end{tabular}

proposto para determinação dos fatores influentes no pagamento de dividendos das empresas brasileiras de capital aberto, e seus resultados estão apresentados na tabela 4 .

Conforme tabela 4 , através dos aspectos contratuais e da legislação brasileira foi possível segmentar a amostra do estudo em três grupos: o grupo MÍNIMO, que paga apenas o dividendo obrigatório legal e contratual, o grupo ACIMA, que paga dividendos acima deste patamar, e a Amostra Completa que engloba todos os eventos estudados.

Adicionalmente, é fato que as empresas do grupo ACIMA são aquelas que, por critérios próprios, decidem pagar proventos extras, ou seja, acima

114 Rev. Bras. Finanças (Online), Rio de Janeiro, V14, No. 1, March 2016 
do obrigatório. São, na nossa opinião, as verdadeiras tomadoras de decisão do pagamento de proventos, visto que as demais (que distribuem apenas o obrigatório) só cumprem o que rege a legislação. Dessa forma, esses critérios e informações podem estar refletidos nos maiores coeficientes de informação de seus modelos, reforçando o conceito desta pesquisa de que a real decisão de pagar dividendos é feita pelas empresas que decidem pagar acima do obrigatório.

O grupo MÍNIMO apresentou as variáveis endividamento, concentração e dividendos do exercício anterior como estatisticamente significantes. Similarmente, o grupo ACIMA apresentou apenas a variável dividendos do exercício anterior. Dessa forma, pode-se perceber que a única variável independente significativa e comum entre os grupos é $D i v_{t-1}$.

Ao examinarmos os coeficientes das três equações, podemos verificar que temos valores com sinais distintos entre os três resultados. A variável concentração apresenta sinal positivo na Amostra Completa e no grupo ACIMA e negativo para o grupo MÍNIMO. Similarmente, as variáveis endividamento e tamanho possuem o mesmo sinal (positivo) para a Amostra Completa e grupo MÍNIMO, mas diferente do grupo ACIMA (negativo). As variáveis ROE, investimento, instabilidade das receitas e dividendo do exercício anterior apresentam a mesma sinalização entre os três grupos.

Cabe ressaltar também a grandeza econômica de alguns coeficientes. Pode-se inferir dos dados provenientes da regressão estimada que a variável Div $v_{t-1}$ causa forte impacto no pagamento de dividendos no Brasil. Seu coeficiente para a Amostra Completa é de $+0,94$ e estatisticamente significante a 0.01 . No grupo ACIMA, a mesma variável também é positiva $(+0,737)$ e significante a 0.01 . Já no grupo MíNIMO, este coeficiente possui menor impacto porém também relevante: positivo $(+0,419)$, e estatisticamente significante a 0.05 . Estes resultados indicam que a variável Div $v_{t-1}$ possui grande impacto no pagamento de dividendos para as empresas brasileiras de capital aberto.

Para a Amostra Completa e grupo MÍNIMO, os coeficientes dos modelos da variável $\mathrm{E}$ apresentaram sinais positivos, fato que contradiz as expectativas iniciais da pesquisa. Conforme a literatura pesquisada, esperava-se que, quanto maior fosse o endividamento da empresa, menor seria a quantidade de dividendos distribuídas a seus acionistas. Inicialmente, poderia-se dizer que este fato não foi corroborado pelos resultados desta pesquisa, visto que os coeficientes dos dois grupos são positivos. Porém, no grupo ACIMA, a variável E possui sinal negativo. É fato que as empresas do 
grupo ACIMA são aquelas que, por critérios próprios, decidem pagar proventos extras, ou seja, acima do obrigatório. Dessa forma, esses critérios e informações podem estar refletidos nos sinais e na grandeza de seus coeficientes, reforçando o conceito desta pesquisa de que a real decisão de pagar dividendos é feita pelas empresas que decidem pagar acima do obrigatório e que a consideração de empresas do grupo MÍNIMO causa importantes impactos nos fatores determinantes de dividendos no Brasil.

Por outro lado, a variável T confirmou as expectativas iniciais da pesquisa apresentando coeficientes positivos para os mesmos dois grupos (Amostra Completa e MÍNIMO). Ou seja, empresas de maior porte estariam distribuindo mais dividendos. Porém, no grupo ACIMA, esta variável apresentou sinal negativo, indicando justamente o oposto. Apesar dos coeficientes desta variável não serem estatisticamente significantes em nenhum grupo, levanta uma questão para futuras pesquisas sobre o tema.

Outro aspecto interessante são as variáveis I e Inst_REC. Os coeficientes das três regressões são negativos. Porém, apenas na Amostra Completa com coeficientes significantes. Apesar da diferenciação entre grupos existir apenas na significância dos coeficientes, os resultados corroboram com as expectativas iniciais. Era esperado justamente resultados negativos, pois segundo a teoria financeira, altos níveis de oportunidade de investimento e instabilidade de receitas reduziriam a propensão ao pagamento de dividendos.

A variável CONC apresentou, conforme esperado, coeficiente positivo para a Amostra Completa e grupo ACIMA. Surpreendentemente, seu coeficiente para o grupo MÍNIMO foi negativo e significante. Este é mais um indicativo que o grupo MÍNIMO apresenta resultados díspares, e que não representam a real decisão de pagar dividendos pelas companhias brasileiras de capital aberto.

Ao notar o sinal distinto nas variáveis nos grupos, temos um forte indicativo que quando são tomados os fatores determinantes da política de dividendos das empresas brasileiras negociadas na BM\&FBovespa pela amostra completa incorremos em erros neste dimensionamento. A Amostra Completa e o grupo ACIMA apresentam resultados muito semelhantes entre si, e díspares quando comparados com o grupo MÍNIMO. É nítido na análise da tabela 4 o impacto do grupo MíNIMO nos coeficientes da Amostra Completa, seja na grandeza ou na significância estatística dos coeficientes. A vontade de pagar dividendos é expressa pela amostra com desejo real de pagamento em valores superiores aos mínimos contratuais e 
legais e não simplesmente pelo Payout total das empresas.

Tabela 5

Tabela com os coeficientes das regressões para os anos amostrais com maior percentual de companhias que distribuíram apenas o dividendo obrigatório (2012) e com menor percentual (2009). A coluna "Variáveis Independentes"demonstra as diversas variáveis apresentadas nesta pesquisa e "Estatísticas"os resultados das regressões. "2012" apresenta os coeficientes da regressão para o ano de 2012, momento em que o Grupo MÍNIMO é maior durante o período amostral. "2009" apresenta os coeficientes da regressão para o ano de 2009, momento em que o Grupo ACIMA é maior durante o período amostral. A coluna "Intervalo de Confiança" apresenta o intervalo com 95\% de confiança dos coeficientes das regressões. Nota: *,**,*** representa coeficientes estatisticamente significantes a $.10, .05$ e 0.1 , respectivamente. Parêntesis representa coeficientes negativos.

\begin{tabular}{lcccc}
\hline $\begin{array}{l}\text { Variáveis } \\
\text { Independentes }\end{array}$ & $\mathbf{2 0 1 2}$ & $\begin{array}{l}\text { Intervalo } \\
\text { Confiança }\end{array}$ & $\mathbf{2 0 0 9}$ & $\begin{array}{l}\text { Intervalo } \\
\text { Confiança }\end{array}$ \\
\hline constante & 0,096 & $(0,297)-0,489$ & 0,163 & $(0,157)-0,483$ \\
\hline ROE & 0,23 & $(0,106)-0,566$ & $0,467^{* * *}$ & $0,216-0,719$ \\
\hline $\mathrm{E}$ & $(0,047)$ & $(0,242)-0,147$ & $(0,002)^{*}$ & $(0,004)-(0,000)$ \\
\hline $\mathrm{T}$ & 0,004 & $(0,022)-0,03$ & 0,006 & $(0,017)-0,03$ \\
\hline $\mathrm{I}$ & $(0,002)$ & $(0,163)-0,16$ & $(0,041)$ & $(0,176)-0,095$ \\
\hline CONC & $(0,001)$ & $(0,003)-0,001$ & 0,001 & $(0,000)-0,002$ \\
\hline INST_REC & 0,035 & $(0,158)-0,228$ & $(0,121)^{*}$ & $(0,254)-0,124$ \\
\hline Div -1 & $0,524^{* * *}$ & $0,304-0,744$ & $0,508^{* * *}$ & $0,347-0,669$ \\
\hline Estatísticas & & & & \\
\hline $\mathrm{n}$ (observações) & 212 & & 233 & \\
\hline R2 & 0,218 & & 0,208 & \\
\hline Média Var. Dep. & 0,443 & & 0,503 & \\
\hline
\end{tabular}

Outra forma de demonstrar o impacto das empresas que pagam apenas o dividendo obrigatório nos fatores determinantes de dividendos está contida na tabela 5. Ao regredir separadamente os anos de 2012 e 2009 (para a amostra completa deste dois anos amostrais), regride-se desta forma os anos com maior percentual de companhias que apenas distribuíram o dividendo obrigatório (2012) e com menor percentual (2009) no período por nós estudado. Dessa forma, cria-se mais um teste para demonstrar o impacto do grupo MÍNIMO nos determinantes de dividendos das companhias brasileiras e na diferenciação dos grupos.

Conforme o esperado, há evidências empíricas que a existência de maior quantidade de empresas que pagam apenas o dividendo obrigatório influencia nos coeficientes da regressão, pois percebe-se diferenças especialmente na grandeza e significância dos coeficientes (principalmente para ROE, E e INST_REC). Nestes coeficientes, existe uma clara diferença de grandeza econômica entre os coeficientes dos dois anos amostrais, fato evidenciado 
pelo intervalo de confiança dos mesmos. Na variável ROE, por exemplo, com $95 \%$ de confiança, o verdadeiro coeficiente desta variável está no intervalo de -0,106 até 0,566 para o ano de 2012. Para 2009, o mesmo intervalo está entre 0,216 e 0,719 . Fica assim evidenciado uma considerável diferença entre coeficientes estimados, visto que o coeficiente de 2012 pode ser até mesmo negativo, o que não ocorre com 2009.

Há também os casos em que o sinal dos coeficientes estão invertidos entre os dois anos (CONC e INST_REC). Estes fatos sinalizam a importância e o cuidado que se deve ter com o dividendo mínimo legal e contratual ao analisarmos os fatores determinantes de dividendos no Brasil.

Ao compararmos os diferentes artigos da Silva (2004), Iquiapaza et al. (2006), Mota \& Eid Junior (2007) que utilizaram a variável Payout para explicar os fatores determinantes de dividendos no Brasil, com a presente pesquisa, algumas considerações devem ser feitas. Apesar do grande número de semelhanças com as pesquisas anteriores que utilizam a variável Payout para explicar os determinantes de pagamentos de dividendos no Brasil, a não consideração do dividendo mínimo pode acarretar alguns vieses importantes. O grupo ACIMA é aquele que, por vontade própria, decide pagar acima do mínimo obrigatório legal e contratual. O grupo MÍNIMO, por sua vez, distribuí apenas o quanto lhe é imposto pela legislação e seu contrato social. E, provavelmente, se pudesse não distribuiria nenhum dividendo, pois são as empresas que apenas cumprem a legislação. Assim, os determinantes de dividendos devem ser avaliados através apenas do grupo ACIMA, desconsiderando as empresas do grupo MíNIMO. Nos trabalhos anteriores, alguns vieses podem ter ocorrido devido a esta consideração. É o exemplo da variável tamanho, que é positiva para a Amostra Completa e grupo MÍNIMO, e positiva para o grupo ACIMA.

O presente estudo é uma evolução dos trabalhos passados sobre determinantes de dividendos. A consideração do dividendo mínimo legal e contratual possui relevante influencia nos fatores determinantes, sendo necessária a sua consideração para entendermos o processo decisório do pagamento de dividendos das empresas brasileiras.

\section{Considerações Finais}

Por muito tempo, os dividendos não eram relevantes para os investidores no Brasil, em decorrência principalmente das altas taxas de inflação vigentes na economia brasileira e ausência de correção monetária sobre os dividendos (Procianoy (2006)). Com a estabilidade dos preços ocorrida na 
economia após 1996, os dividendos passaram a ser mais valorizados, ganhando destaque nos portfólios das empresas Assaf Neto (2007).

Vários estudos (Heineberg \& Procianoy (2003), da Silva (2004), Iquiapaza et al. (2005, 2006), Mota \& Eid Junior (2007), Ferreira Júnior et al. (2010), Forti et al. (2014)) buscaram identificar os fatores determinantes do pagamento de dividendos no Brasil. Estas pesquisas avaliaram quais fatores influenciaram a distribuição de proventos das companhias brasileiras de capital aberto. Com uma perspectiva diferente destes, o presente trabalho procurou estudar os fatores determinantes de dividendos sob um novo prisma, conectando ao tema a questão legal (legislação) e contratual (estatuto social das empresas) sobre o assunto. Para, dessa forma, demonstrar que existem diferenças fundamentais entre os diferentes grupos estudados.

Conforme o esperado preliminarmente, há fortes evidências empíricas que as empresas que pagam dividendos acima do obrigatório legal e contratual são diferentes das empresas que pagam apenas este. Dessa forma, a existência de empresas na amostra que pagam apenas o dividendo obrigatório influencia nos coeficientes da regressão da Amostra Completa, pois percebe-se diferenças especialmente na grandeza e significância dos coeficientes para as regressões do grupo ACIMA e MÍNIMO.

Assim, é de suma importância pesquisar as empresas que decidem distribuir dividendos (aquelas que pagam acima do mínimo legal e contratual), pois estas tomam a real decisão de distribuição. Consequentemente, são também as empresas que devem ser estudadas para a obtenção dos fatores determinantes de dividendos. Como demonstrado ao longo desta pesquisa, a inclusão das empresas que pagam apenas o mínimo acarreta em vieses importantes nos resultados das regressões, tanto em temos de sinal dos coeficientes, quanto em magnitude e significância. Por isso, consideramos a presente pesquisa um avanço no estudo dos fatores que influenciam as empresas brasileiras de capital aberto a pagarem proventos ao abordarmos e considerarmos a legislação que tanto influencia o tema.

\section{Referências}

Aivazian, Varouj, Booth, Laurence, \& Cleary, Sean. 2003. Do emerging market firms follow different dividend policies from U.S. firms? Journal of Financial research, 26(3), 371-387.

Alli, Kasim L, Khan, A Qayyum, \& Ramirez, Gabriel G. 1993. Deter- 
minants of corporate dividend policy: a factorial analysis. Financial Review, 28(4), 523-547.

Assaf Neto, Alexandre e Ambrozini, Marcelo Augusto e Lima FG. 2007. Dividendos: teoria e prática. Ribeirão Preto: Inside Books.

Bhattacharya, Sudipto, et al. 1979. Imperfect information, dividend policy, and "the bird in the hand" fallacy. Bell journal of economics, 10(1), 259-270.

Black, Fischer. 1976. The dividend puzzle. The Journal of Portfolio Management, 2(2), 5-8.

Bond, Stephen R. 2002. Dynamic panel data models: a guide to micro data methods and practice. Portuguese economic journal, 1(2), 141-162.

Brown, Kate, \& Sum, Vichet. 2010. Determinants of dividend payments. International Journal of Applied Accounting and Finance, 1(1), 40-46.

Coelho, Fábio Ulhoa. 2002. Curso de direito comercial. Vol. 1. Saraiva.

Correia da Silva, Luis, Goergen, Marc, \& Renneboog, Luc. 2004. Dividend policy and corporate governance. Oxford University Press.

da Silva, André Luiz Carvalhal. 2004. Governança corporativa, valor, alavancagem e política de dividendos das empresas brasileiras. Revista de Administra\&ccdeil; ão da Universidade de São Paulo, 39(4).

Dalmácio, Flávia Zóboli, \& Corrar, Luiz João. 2007. A concentração do controle acionário e a política de dividendos das empresas listadas na Bovespa: uma abordagem exploratória à luz da teoria de agência. Revista de Contabilidade e Organizações, 1(1), 16-29.

Denis, David J, \& Osobov, Igor. 2008. Why do firms pay dividends? International evidence on the determinants of dividend policy. Journal of Financial Economics, 89(1), 62-82.

Downing, Douglas, Clark, Jeffrey, \& de Farias, Alfredo Alves. 1999. Estatística aplicada. Saraiva.

Fama, Eugene F. 1974. The empirical relationships between the dividend and investment decisions of firms. The American Economic Review, 304-318.

120 Rev. Bras. Finanças (Online), Rio de Janeiro, V14, No. 1, March 2016 
Fama, Eugene F, \& French, Kenneth R. 2001. Disappearing dividends: changing firm characteristics or lower propensity to pay? Journal of Financial economics, 60(1), 3-43.

Ferreira Júnior, WO, Martin, DML, Nakamura, WT, \& Bastos, DD. 2010. Evidências empíricas dos fatores determinantes das políticas de dividendos das firmas listadas na Bovespa. Facef Pesquisa. Franca, 13(2).

Forti, Cristiano, Peixoto, Fernanda, \& Alves, Denis. 2014. Pagamento de dividendos no Brasil: um estudo empírico sobre seus determinantes. XIV Ebfin.

Frankfurter, George, Wood, Bob G, \& Wansley, James. 2003. Dividend policy: Theory and practice. Academic Press.

Futema, Mariano Seikitsi, Basso, Leonardo Fernando Cruz, \& Kayo, Eduardo Kazuo. 2009. Estrutura de capital, dividendos e juros sobre o capital próprio: testes no Brasil. Revista Contabilidade \& Finanças, 20(49), 4462.

Good, Phillip I, \& Hardin, James W. 2012. Common errors in statistics (and how to avoid them). John Wiley \& Sons.

Gordon, Myron J. 1963. Optimal Investing and Financing Policy. The Journal of finance, 18(2), 264-272.

Hahn, Aucilene Vasconcelos, Nossa, Silvania Neris, Teixeira, Aridelmo JC, \& Nossa, Valcemiro. 2010. Um Estudo sobre a relação entre a concentração acionária e o nível de payout das empresas brasileiras negociadas na Bovespa. Contabilidade Vista \& Revista, 21(3), 15-48.

Hair, Joseph F, Black, William C, Babin, Barry J, Anderson, Rolph E, \& Tatham, Ronald L. 2009. Análise multivariada de dados. Bookman.

Heineberg, Ricardo, \& Procianoy, Jairo Laser. 2003. Aspectos Determinantes do Pagamento de Proventos em Dinheiro das Empresas com Ações Negociadas na Bovespa. XXVII ENANPAD.

Iquiapaza, Robert, Bressan, Aureliano Angel, Gerais, Minas, \& Barbosa, Francisco Vidal. 2005. Dividendos: Plano Real, Imposto De Renda E Sinalização Nas Empresas Listadas Na Bovespa: 1986 A 2003. V EBFin. 
Iquiapaza, Robert, Lamounier, Wagner, \& Amaral, Hudson. 2006. Assimetria de informações e pagamento de proventos na Bovespa. University Library of Munich.

Iudícibus, Sérgio de, Martins, Eliseu, Gelbcke, Ernesto Rubens, \& Santos, Ariovaldo dos. 2010. Manual de contabilidade societária. São Paulo: Atlas.

La Porta, Rafael, Lopez-de Silanes, Florencio, Shleifer, Andrei, \& Vishny, Robert. 2000. Investor protection and corporate governance. Journal of financial economics, 58(1), 3-27.

Lintner, John. 1956. Distribution of incomes of corporations among dividends, retained earnings, and taxes. The American Economic Review, 97-113.

Lintner, John. 1962. Dividends, earnings, leverage, stock prices and the supply of capital to corporations. The Review of Economics and Statistics, 243-269.

Lusk, Edward J, Halperin, Michael, \& Heiling, F. 2011. A note of power differentials in data preparation between trimming and winsorizing. $\mathrm{Bu}$ siness Management Dynamics, 1(2), 23-31.

Miller, Merton H, \& Modigliani, Franco. 1961. Dividend policy, growth, and the valuation of shares. the Journal of Business, 34(4), 411-433.

Morck, Randall, Shleifer, Andrei, \& Vishny, Robert W. 1988. Management ownership and market valuation: An empirical analysis. Journal of financial economics, 20, 293-315.

Mota, Daniel Camarotto, \& Eid Junior, Willian. 2007. Dividendos, juros sobre capital póprio e recompra de ações: um estudo empírico sobre a política de distribuição no Brasil. XXXIV Enanpad.

Procianoy, Jairo Laser. 2006. A política de dividendos e o preço das ações. Gestão de investimentos e fundos. Rio de Janeiro: Financial, 39-164.

Procianoy, Jairo Laser, \& Vancin, Daniel. 2014. Dividends: Publicly Listed Brazilian Companies' Propensity to Pay or Not to Pay. Available at SSRN 2447972. 
Redding, Lee S. 1997. Firm size and dividend payouts. Journal of Financial Intermediation, 6(3), 224-248.

Requião, Rubens. 2011. A distribuição de lucros nas sociedades anônimas. Pages 1305-1310 of: Wald, Arnoldo (ed), Direito empresarial: sociedades anônimas. Editora Revista dos Tribunais.

Santos, Ariovaldo dos, \& Salotti, Bruno Meirelles. 2009. Juros sobre o capital Próprio-Pesquisa Empírica Para Avaliação do nível de conhecimento das Empresas sobre sua utilização. Contabilidade, Gestão e Governança, 10(2).

Silva, Júlio Cesar G da, \& Brito, Ricardo D. 2005. Testando as previsões de trade-off e pecking order sobre dividendos e dívida no Brasil. Estudos Econômicos (São Paulo), 35(1), 37-79. 